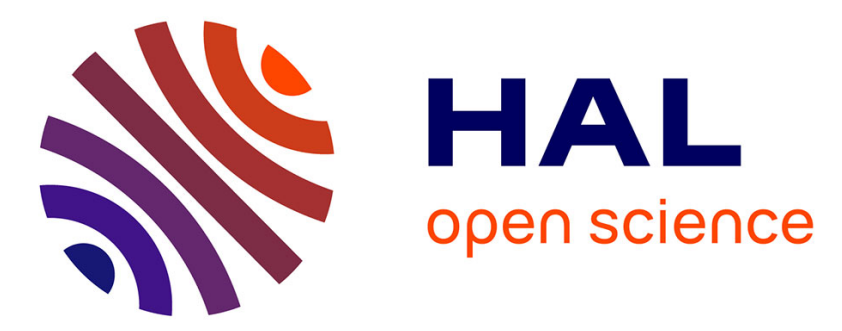

\title{
ANALYTICAL MODELS AND ELECTRICAL CHARACTERISATION OF ADVANCED MOSFETS IN THE QUASI BALLISTIC REGIME
}

Raphael Clerc, Gérard Ghibaudo

\section{- To cite this version:}

Raphael Clerc, Gérard Ghibaudo. ANALYTICAL MODELS AND ELECTRICAL CHARACTERISATION OF ADVANCED MOSFETS IN THE QUASI BALLISTIC REGIME. International Journal of High Speed Electronics and Systems, 2013, 22 (1), pp.1350002. 10.1142/S012915641350002X . hal-00917094

\author{
HAL Id: hal-00917094 \\ https://hal.science/hal-00917094
}

Submitted on 11 Dec 2013

HAL is a multi-disciplinary open access archive for the deposit and dissemination of scientific research documents, whether they are published or not. The documents may come from teaching and research institutions in France or abroad, or from public or private research centers.
L'archive ouverte pluridisciplinaire HAL, est destinée au dépôt et à la diffusion de documents scientifiques de niveau recherche, publiés ou non, émanant des établissements d'enseignement et de recherche français ou étrangers, des laboratoires publics ou privés. 


\title{
ANALYTICAL MODELS AND ELECTRICAL CHARACTERISATION OF ADVANCED MOSFETS IN THE QUASI BALLISTIC REGIME
}

\author{
RAPHAEL CLERC \\ Laboratoire Hubert Curien (UMR 5516 CNRS) \\ Institut d'Optique \& Université Jean-Monnet \\ Rue du Professeur Benoit Lauras, 42000, Saint-Etienne, France \\ raphael.clerc@institutoptique.fr \\ GERARD GHIBAUDO \\ IMEP LAHC (UMR 5130 CNRS) \\ Grenoble INP, Minatec \\ 3, rue Parvis Louis Néel, 38000 Grenoble, France \\ ghibaudo@minatec.inpg.fr
}

\begin{abstract}
The quasi-ballistic nature of transport in end of the roadmap MOSFETs device is expected to lead to significant on state current enhancement. The current understanding of such mechanism of transport is carefully reviewed in this chapter, underlining the derivation and limits of corresponding analytical models. In a second part, different strategies to compare these models to experiments are discussed, trying to estimate the "degree of ballisticity" achieved in advanced technologies.
\end{abstract}

Keywords: Advanced MOSFETs, Quasi Ballistic transport, Electrical Characterization, Neutral Defects

\section{Introduction}

Since 2003, the ITRS roadmap has considered the Quasi Ballistic (QB) regime of transport as a possible "technological booster" of MOSFET performances ${ }^{1}$. Indeed, the physics of quasi ballistic transport was expected to lead to enhanced on state drive current $\mathrm{I}_{\mathrm{on}}$, compared to prediction based on the conventional drift diffusion theory. At very short channel length, as illustrated on Figure 1, the commonly used drift diffusion theory ${ }^{2}$ predicts a saturation of the on current versus channel length, due to the mechanism of velocity saturation $\left(\mathrm{v}_{\mathrm{sat}}\right)^{3}{ }^{4}$. The drift diffusion theory is based on a low field simplification of the semiclassical Boltzmann Transport Equation ${ }^{2}$ and empirically accounts for the phenomenon of saturation velocity observed in long samples at high field condition, by introducing a longitudinal field dependent mobility equation ${ }^{56}$. This approach has been successfully applied to model relatively long device, but it does not apply at channel length comparable or lower than the mean free path $\lambda$. In this regime, the more appropriate ballistic theory also predicts a saturation of current for $\mathrm{L}<<\lambda$ (called the ballistic limit), but at a higher level and for different reasons ${ }^{78}$. In addition, present devices are more likely to operate in the transition regime where $L \sim \lambda$, referred to as the quasi-ballistic regime ${ }^{8}$. The ratio between the quasi-ballistic current and the drift diffusion current is named the Ballistic Enhancement Factor (BEF), a quantity of great interest for device technology, always looking for any possible source of on state current enhancement.

The accurate evaluation of the BEF versus device characteristic requires highly sophisticated numerical models, accounting for quantum confinement within the channel 


\section{Raphaël Clerc, Gérard Ghibaudo}

and non-equilibrium transport physics, including all relevant scattering mechanisms. Extensive researches have been carried out in the last ten years to design such codes. To this purpose, two main physical models have been investigated. The first one consists in solving the Boltzmann Transport Equation, either by the Multi Subband Monte Carlo method $^{910} 11$ or by direct solving techniques ${ }^{12}$. In this semiclassical approach, the implementation of scattering mechanism is relatively well known and can be calibrated on experiments performed on large devices. However, longitudinal quantum effects can only be accounted for by means of subtle approximations. The second approach consists in solving the Schrodinger equation by the Non Equilibrium Green Function formalism ${ }^{13}$ ${ }^{14}$, which rigorously captures the wave nature of electron and hole transport, but makes difficult the implementation of scattering mechanisms, especially when devices larger than few nanometers are considered. Despite huge efforts in the last years, these models are still in progress, especially to account for full band and mechanical strain effects. In addition, these codes are extremely time consuming, requiring extensive parallel computing, and are not available yet in commercial tools.

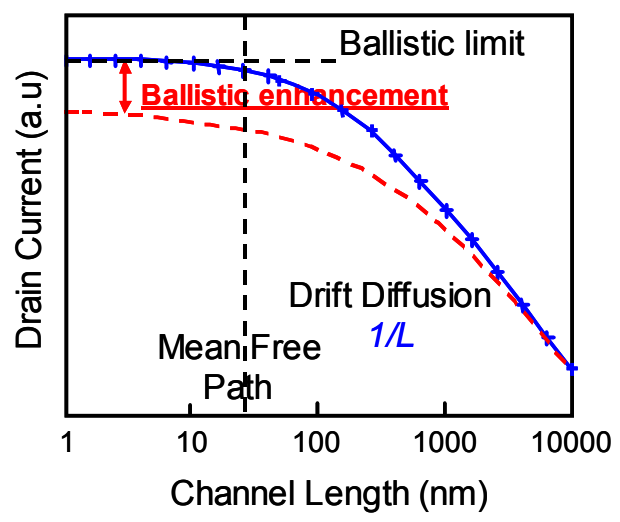

Figure 1 : Schematic representation of the expected evolution of a MOSFET device on state current $\mathrm{I}_{\text {on }}$ versus channel length.

In this context, it is of great importance to develop approximated analytical models, which can capture the main features of quasi-ballistic transport. Such models could estimate in first order approximation what could be the Ballistic Enhancement Factor versus technological options. In addition, parameter extraction procedures from electrical measurements have also to be improved, in order to quantify the degree of ballisticity really achieved in advanced technologies. Both topics are addressed in this chapter.

The conventional Natori Lundstrom model of Quasi Ballistic transport will be described in the next section. Its limits are then investigated in paragraph 3. Finally, the experimental procedures used to quantify the degree of ballisticity in linear region will be discussed in the final section. 


\section{The Natori - Lundstrom models of Quasi Ballistic Transport}

\subsection{The Natori model of ballistic transport}

Well known in the area of basic Physics ${ }^{15}$, since the pioneering work of Landauer ${ }^{16}$, the concept of ballistic limit has been re-investigated in the context of MOSFET devices by Natori ${ }^{17}$ in 1994. His approach relies on the idea that transport into a ballistic device is no longer limited by the channel, but by the mechanism of carrier injection into it ${ }^{815} 17$. It is based on two main assumptions: 1/ device source and drain are supposed to be ideal reservoirs of carriers in equilibrium conditions, $2 /$ the gate is supposed to control perfectly the barrier between source and channel, as in well-designed device with negligible short channel effects. Under these hypothesis, the semi classical flux of carrier $\mathrm{F}_{\mathrm{s}}^{+}$emitted from the source in equilibrium and entering through the channel (at a point called "virtual source") can easily be computed in a (100) Si electron channel, leading to:

$$
\mathrm{F}_{\mathrm{s}}^{+}=\frac{(2 \mathrm{kT})^{3 / 2}}{\pi^{2} \hbar^{2}}\left[\sum_{\mathrm{i}} \sqrt{\mathrm{m}_{\mathrm{cL}}} \mathrm{F}_{1 / 2}\left(\frac{\mathrm{E}_{\mathrm{Fs}}-\mathrm{E}_{\mathrm{i}}^{\mathrm{L}}}{\mathrm{kT}}\right)+\sum_{\mathrm{i}} \sqrt{\mathrm{m}_{\mathrm{cT}}} \mathrm{F}_{1 / 2}\left(\frac{\mathrm{E}_{\mathrm{Fs}}-\mathrm{E}_{\mathrm{i}}^{\mathrm{T}}}{\mathrm{kT}}\right)\right]
$$

where $\mathrm{m}_{\mathrm{cL}}=\mathrm{m}_{\mathrm{t}}, \mathrm{m}_{\mathrm{cT}}=\left(\mathrm{m}_{1}{ }^{1 / 2}+\mathrm{m}_{\mathrm{t}}{ }^{1 / 2}\right)^{2} \cdot \mathrm{F}_{1 / 2}$ is a Fermi integral of order $1 / 2, \mathrm{E}_{\mathrm{i}}^{\mathrm{L}}\left(\right.$ resp. $\left.\mathrm{E}_{\mathrm{i}}^{\mathrm{T}}\right)$ are the unprimed (resp. primed) subband energies, $i$ the subband index. In this one dimensional approach, in full ballistic regime, as the positive $\mathrm{k}$ states of the conduction band are populated by carriers emitted by the source, the carrier density $\mathrm{N}_{\mathrm{s}}{ }^{+}$flowing from source to drain is given by:

$$
\mathrm{N}_{\mathrm{s}}^{+}\left(\mathrm{E}_{\mathrm{Fs}}\right)=\sum_{\mathrm{i}} \frac{1}{2} \frac{\mathrm{m}_{\mathrm{dL}}}{\pi \hbar^{2}} \mathrm{kT} \mathrm{F}_{0}\left(\frac{\mathrm{E}_{\mathrm{Fs}}-\mathrm{E}_{\mathrm{i}}^{\mathrm{L}}}{\mathrm{kT}}\right)+\sum_{\mathrm{i}} \frac{1}{2} \frac{\mathrm{m}_{\mathrm{dT}}}{\pi \hbar^{2}} \mathrm{kT} \mathrm{F}_{0}\left(\frac{\mathrm{E}_{\mathrm{Fs}}-\mathrm{E}_{\mathrm{i}}^{\mathrm{T}}}{\mathrm{kT}}\right)
$$

where $\mathrm{m}_{\mathrm{dL}}=2 \mathrm{~m}_{\mathrm{t}}$ and $\mathrm{m}_{\mathrm{dT}}=\left(\mathrm{m}_{\mathrm{l}} \mathrm{m}_{\mathrm{t}}\right)^{1 / 2}$. Similarly, as a difference of potential $\mathrm{V}_{\mathrm{ds}}$ is applied between source and drain, the negative carriers density emitted by the drain and reaching the source end is given by

$$
\mathrm{N}_{\mathrm{d}}^{-}\left(\mathrm{E}_{\mathrm{Fs}}, \mathrm{V}_{\mathrm{ds}}\right)=\sum_{\mathrm{i}} \frac{1}{2} \frac{\mathrm{m}_{\mathrm{dL}} \mathrm{kT}}{\pi \hbar^{2}} \mathrm{~F}_{0}\left(\frac{\mathrm{E}_{\mathrm{Fs}}-\mathrm{qV}_{\mathrm{ds}}-\mathrm{E}_{\mathrm{i}}^{\mathrm{L}}}{\mathrm{kT}}\right)+\frac{1}{2} \frac{\mathrm{m}_{\mathrm{dT}} \mathrm{kT}}{\pi \hbar^{2}} \mathrm{~F}_{0}\left(\frac{\mathrm{E}_{\mathrm{Fs}}-\mathrm{qV}_{\mathrm{ds}}-\mathrm{E}_{\mathrm{i}}^{\mathrm{T}}}{\mathrm{kT}}\right)
$$

In a well-designed MOSFET with negligible short channel effect, the charge at the virtual source remains constant when a bias $\mathrm{V}_{\mathrm{ds}}$ is applied between source and drain. In consequence, the parameter $\mathrm{E}_{\mathrm{Fs}}$ is adjusted in order to maintain a constant total charge $\mathrm{Q}_{\mathrm{i}}$ at this point, as explained in details in references 18 and 19, solving the equation:

$$
\mathrm{Q}_{\mathrm{i}}=\mathrm{q} \mathrm{N} \mathrm{N}_{\mathrm{s}}^{+}\left(\mathrm{E}_{\mathrm{Fs}}\right)+\mathrm{q} \mathrm{N}-\left(\mathrm{E}_{\mathrm{Fs}}, \mathrm{V}_{\mathrm{ds}}=0\right)=\mathrm{q} \mathrm{N} \mathrm{N}_{\mathrm{s}}^{+}\left(\mathrm{E}_{\mathrm{Fs}}\right)+\mathrm{q} \mathrm{N} \mathrm{N}_{\mathrm{d}}^{-}\left(\mathrm{E}_{\mathrm{Fs}}, \mathrm{V}_{\mathrm{ds}}\right)
$$

This procedure emulates the action of source - channel barrier modulation induced by the gate electrostatics. At $\mathrm{V}_{\mathrm{ds}}=0, \mathrm{E}_{\mathrm{Fs}}$ coincides with the inversion layer Fermi level. At last, the ballistic current $I_{d}{ }^{B A L}$ flowing from source to drain is simply given by:

$$
\mathrm{I}_{\mathrm{d}}^{\mathrm{BAL}}=\mathrm{q}\left(\mathrm{F}_{\mathrm{s}}^{+}-\mathrm{F}_{\mathrm{d}}^{-}\right)
$$


where $\mathrm{F}_{\mathrm{d}}^{-}$is the flux of carrier emitted from the drain to the source. $\mathrm{F}_{\mathrm{d}}{ }^{-}$has a similar expression than Eq. (1), except that, as carriers are emitted by the drain, the parameter $\mathrm{E}_{\mathrm{Fd}}$ is equal to $\mathrm{E}_{\mathrm{Fs}}-\mathrm{qV}_{\mathrm{ds}}$.

Initially derived by Natori in the quantum limit regime (one single subband, completely degenerated), this model has been generalized in the more generalized case of multi subband inversion layer ${ }^{18}$, and for various materials, arbitrary oriented ${ }^{24}$. To compute the energy level $\mathrm{E}_{\mathrm{i}}$ entering in Eq. (1), the numerical solution of the coupled Poisson and Schrodinger equations at the virtual source is required. However, it can also be achieved by suitable analytical models, such as the models derived for bulk ${ }^{21}$, Fully Depleted $\mathrm{SOI}^{22}$ and double gate transistors ${ }^{23}$.

In the subthreshold regime, this model only accounts for ideal thermionic emission in a well-designed MOSFET. A detailed modelling of the potential barrier between source and drain is thus required to include also the impact of short channel effects, band to band tunnelling and source to drain tunnelling ${ }^{24} 25$.

\subsection{Injection velocity and subband engineering}

The ratio between the flux of carriers emitted by the source and entering the channel, divided by the corresponding carrier density is usually called the injection velocity $\mathrm{V}_{\text {inj. }}$. $\left(\mathrm{V}_{\mathrm{inj}}=\mathrm{F}_{\mathrm{s}}^{+} / \mathrm{N}_{\mathrm{s}}^{+}\right)$. The injection velocity, computed by the Natori model, has been found in good agreement with the injection velocity extracted from Multi Subband Monte Carlo simulations (see figure 2), when devices featuring negligible short channel effects are considered. Note that in the high field conditions (corresponding to the transistor on state), as the drain is no longer emitting carriers capable of reaching the source, $\mathrm{I}_{\mathrm{d}}{ }^{\mathrm{BAL}} \sim$ $\mathrm{qF}_{\mathrm{s}}^{+} \sim \mathrm{Q}_{\mathrm{i}} \mathrm{V}_{\mathrm{inj}}$. In the ballistic regime, the Ballistic Enhancement Factor is thus simply given by:

$$
\mathrm{BEF}_{\mathrm{BAL}}=\frac{\mathrm{v}_{\mathrm{inj}}}{\mathrm{v}_{\mathrm{sat}}}
$$

where $\mathrm{v}_{\text {sat }}$ is the saturation velocity.

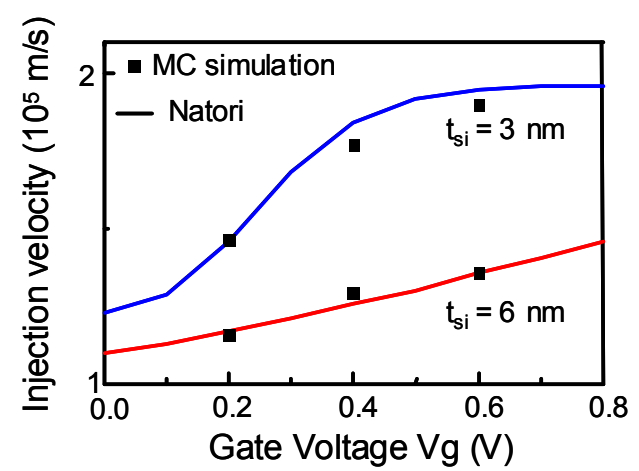

Figure 2 : Comparison between injection velocity extracted from Multi Subband Monte Carlo simulations and calculated according the Natori model on undoped Double Gate MOSFET with silicon body $\mathrm{t}_{\mathrm{si}}=3 \mathrm{~nm}$ (resp. 6 $\mathrm{nm}$ ), channel length $\mathrm{L}=18 \mathrm{~nm}$ (resp. $28 \mathrm{~nm}$ ), and $\mathrm{t}_{\mathrm{ox}}=0.9 \mathrm{~nm}, \mathrm{~V}_{\mathrm{d}}=0.6 \mathrm{~V}$ (see ref. 19 for details). 
In weak inversion regime, the distribution of carrier at the virtual source follows a Maxwellian distribution. In this case, the injection velocity is equal to the thermal velocity, given for (100) silicon conduction band by:

$$
\mathrm{v}_{\mathrm{th}}=\frac{2}{3} \sqrt{\frac{2 \mathrm{kT}}{\pi \mathrm{m}_{\mathrm{t}}}}+\frac{1}{3} \sqrt{\frac{2 \mathrm{kT}}{\pi \mathrm{m}_{\mathrm{l}}}} \approx 10^{5} \mathrm{~m} / \mathrm{s}
$$

As already pointed out in ref. 7, in the case of silicon, the value of the thermal velocity, by pure hazard, is very close to the one of the saturation velocity $\mathrm{v}_{\mathrm{sat}}$. The consequence of such fortuity will be discussed later on. Note that this is usually not the case in other semiconductor materials, such as Germanium for instance.

In strong inversion regime however, the electron gas at the virtual source becomes degenerated. In this case, as high energetic states become more and more populated, the injection velocity tends to increase, as shown in Figure 2, exceeding the thermal velocity, and consequently the saturation velocity itself ${ }^{19}$.

This phenomenon has received a considerable attention, as it is expected to increase the Ballistic Enhancement Factor. It is indeed possible, in principle, to further enhance the injection velocity by reducing the virtual source density of states (DOS), a procedure sometimes referred to as "subband engineering" 26 . Indeed, for the same amount of charges, states of higher energy would be more populated in a lower DOS than in a larger DOS device ${ }^{19}$.

Several strategies are possible to reduce channel DOS. The first one would consist in reducing the number of populated subbands at the virtual source, by enhancing confinement. As seen in figure 3, the average injection velocity is indeed penalized by the contribution of other subbands, especially when they are not degenerated. Extremely thin SOI substrate can thus be used in order to reduce the number of populated subband ${ }^{19} 26$. Another technique consists in introducing mechanical strain ${ }^{21}$, or simply using of low DOS alternative channel material 2026272829 . Although the last option would be certainly the most effective in term of improvement of injection velocity (see figures $4 \& 5$ ), it would also require a radical change of the technology. This option is nevertheless currently extensively investigated at the research level ${ }^{30} 31$.

Among the other "more conventional" options, the strain appears to be the most effective (see figure 4): an ideal biaxial strain for electrons for instance would lead to a $40 \%$ improvement $^{19}$, while the enhancement of quantum effect due to the scaling of the body thickness down to $6 \mathrm{~nm}$ in Ultra Thin Body technologies would only lead to a $15 \%$ improvement at best. The little impact of body thickness reduction is partially due to the effect of the wave function penetration through the gate dielectric due to tunneling ${ }^{32}{ }^{33}$, which tends to relax quantum confinement. 


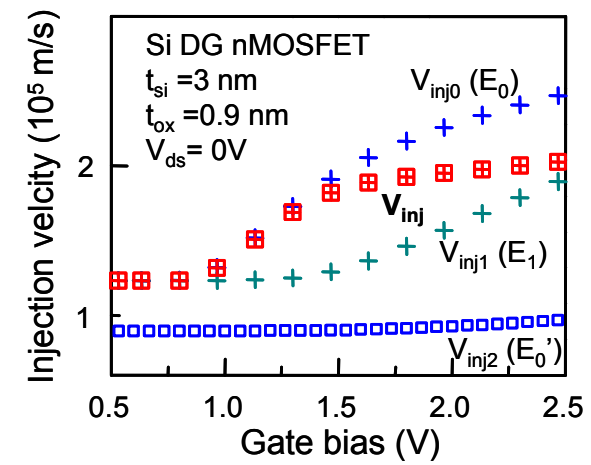

Figure 3 : Gobal injection velocity versus gate voltage in double gate MOSFETs of $3 \mathrm{~nm}$ of body thickness. The injection velocity of the first three subbands is also shown for comparison, showing that the global injection velocity is lower than the first subband injection velocity, when the other subbands starts to be populated.

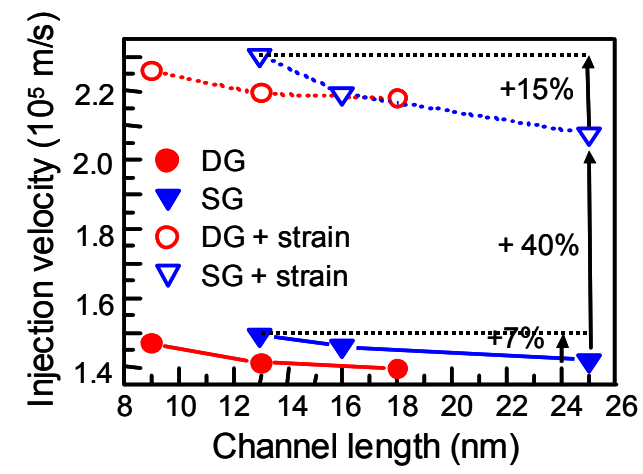

Figure 4 : Injection velocity along the roadmap in Single Gate and Double gate MOSFETs devices, with and without biaxially strained channels

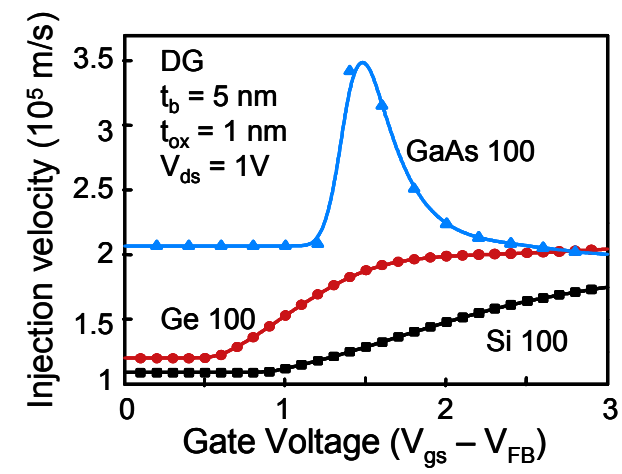

Figure 5 : Injection velocity for nMOS Double Gate transistor, computed versus gate voltage, for (100) Si, (100) Ge and (100) GaAs materials. All relevant valleys $\Gamma, \Lambda, \Delta$ are included in the Poisson Schrodinger calculation

However, the implication of subband engineering investigated using the Natori model should been considered with care, for several reasons. First of all, the Ballistic Enhancement Factor, which quantifies the enhancement of on state current due to 
ballistic transport versus drift diffusion simulation, is not the only figure of merit of a given technology. As far as CMOS is concerned, the $\mathrm{I}_{\text {on }}-\mathrm{I}_{\text {off }}$ trade-off remains of course of primary importance. In this context, let us remind that first of all, low DOS devices usually also suffer, from the same reasons, to an enhancement of Dark Space phenomenon, which tends to further degrade the gate-to-substrate coupling 29343536 . In addition, alternative channel materials are also penalized by an increase of off state currents (Band to Band and Source to Drain Tunneling), especially at gate length below $15 \mathrm{~nm}^{24} 2537$. Moreover, when the gate does not perfectly control the charge at the virtual source, which is unfortunately often the case in real devices, the injection velocity tends to further increase. In addition to DIBL, the virtual source itself can also be heated by field. These phenomena have been observed in several Monte Carlo simulations ${ }^{38-45}$, and are not completely understood yet. Finally, the assumption of full ballistic transport still remains quite unrealistic ${ }^{38-45}$. For instance, results in ref. 40 have revealed that even a defect - free $10 \mathrm{~nm}$ undoped silicon channel cannot be considered as purely ballistic, and that the on state current has been indeed found $20 \%$ lower than the ballistic current. Improvements of the Natori model to account for scattering will be thus discussed in the next section.

\subsection{Lundstrom models of backscattering}

To account for scattering, the Natori model has been improved by Lundstrom and co worker $^{7} 8$ using the "flux theory of transport", an approach initially introduced by McKelvey ${ }^{46}$. The key parameter of this new approach is the backscattering coefficient $r$, namely the ratio between the flux of carrier re injected to the source by scattering, divided by the flux of carrier injected by the source. This parameter can easily be introduced into the Natori model. First of all, assuming that it has the same value at the source and drain ends, the current flowing through the device can be expressed as:

$$
\mathrm{I}_{\mathrm{d}}^{\mathrm{QBAL}}=\mathrm{q}\left[\mathrm{F}_{\mathrm{s}}^{+}-\mathrm{rF}_{\mathrm{s}}^{+}-(1-\mathrm{r}) \mathrm{F}_{\mathrm{d}}^{-}\right]
$$

The procedure for determining $\mathrm{E}_{\mathrm{Fs}}$ has also to be modified, in order to account for backscattered carriers. In consequence, equation (4) becomes:

$$
\mathrm{Q}_{\mathrm{i}}=\mathrm{q} \mathrm{N}_{\mathrm{s}}^{+}\left(\mathrm{E}_{\mathrm{Fs}}\right)\left(1+\mathrm{r}\left(\mathrm{V}_{\mathrm{ds}}\right)\right)+\mathrm{q} \mathrm{N}_{\mathrm{d}}^{-}\left(\mathrm{E}_{\mathrm{Fs}}, \mathrm{V}_{\mathrm{ds}}\right)\left(1-\mathrm{r}\left(\mathrm{V}_{\mathrm{ds}}\right)\right)
$$

Under particular bias conditions, these two equations can be further simplified. In ohmic regime, $\mathrm{Q}_{\mathrm{i}} \sim 2 \mathrm{q} \mathrm{N}_{\mathrm{s}}{ }^{+}$. Assuming non degenerated statistics, and recalling that $\mathrm{V}_{\mathrm{inj}}=$ $\mathrm{F}_{\mathrm{s}}^{+} / \mathrm{N}_{\mathrm{s}}^{+}=\mathrm{v}_{\mathrm{th}}$, equation (8) simply reduces to:

$$
\mathrm{I}_{\mathrm{d}}^{\mathrm{QBAL}} \operatorname{lin}=\left(1-\mathrm{r}_{\text {lin }}\right) \frac{\mathrm{Q}_{\mathrm{i}}}{2} \mathrm{v}_{\mathrm{th}} \frac{\mathrm{q} \mathrm{V}_{\mathrm{ds}}}{\mathrm{kT}}
$$

In high field (saturation) regime however, the contribution to the total current of electron emitted by the drain can be neglected. In consequence:

$$
\mathrm{I}_{\mathrm{d}}^{\mathrm{QBAL}} \text { sat }=\frac{1-\mathrm{r}_{\mathrm{sat}}}{1+\mathrm{r}_{\mathrm{sat}}} \mathrm{Q}_{\mathrm{i}} \mathrm{V}_{\mathrm{inj}}
$$

The ballistic enhancement ratio, in the quasi-ballistic regime, is thus equal to: 


$$
\mathrm{BEF}_{\mathrm{QBAL}}=\frac{1-\mathrm{r}_{\mathrm{sat}}}{1+\mathrm{r}_{\mathrm{sat}}} \frac{\mathrm{v}_{\mathrm{inj}}}{\mathrm{v}_{\text {sat }}}
$$

Simple models have been proposed to estimate this backscattering coefficient. In low source to drain field condition, assuming a constant mean free path $\lambda$ (average distance between two scattering events) and non degenerated statistics, it can be demonstrated using the flux theory ${ }^{215}$ that:

$$
\mathrm{r}_{\mathrm{LF}}=\frac{\mathrm{L}}{\mathrm{L}+\lambda}
$$

In high field conditions, arguing that after a critical distance $\mathrm{L}_{\mathrm{kT}}$, scattering events would no longer be efficient enough to re-inject carrier back to the source because of the source to drain electric field attraction, the previous formula has been extended to high field condition, by substituting the channel length $\mathrm{L}$ by the critical distance $\mathrm{L}_{\mathrm{kT}}$, leading to:

$$
\mathrm{r}_{\mathrm{HF}}=\frac{\mathrm{L}_{\mathrm{kT}}}{\mathrm{L}_{\mathrm{kT}}+\lambda}
$$

This critical distance has been estimated as the distance needed by the potential to drop of a quantity of kT/q from the virtual source. Finally, the constant mean free path $\lambda$ has been taken equal to:

$$
\lambda=\frac{2 \mu}{\mathrm{v}_{\mathrm{th}}} \frac{\mathrm{kT}}{\mathrm{q}}
$$

where $\mu$ is the low field long channel mobility, a particular value that allow to match, both in high field and low field conditions, the ballistic (when $\mathrm{L}$ or $\mathrm{L}_{\mathrm{kT}}<<\lambda$ ) and drift diffusion (when $\mathrm{L}$ or $\mathrm{L}_{\mathrm{kT}}>>\lambda$ ) limit expressions (see figure 6). Formula (15) indicates that the low field long channel mobility $\mu$ is still a relevant parameter to improve performances, even in far from equilibrium regime of transport and in high field conditions. In addition, combining equations (10) (13) and (15) leads to a simple expression of the quasi ballistic current in the linear regime:

$$
\mathrm{I}_{\mathrm{d}}^{\mathrm{QBAL}} \operatorname{lin}=\frac{\mu^{\prime}(\mathrm{L})}{\mathrm{L}} \mathrm{Q}_{\mathrm{i}} \mathrm{V}_{\mathrm{ds}} \quad \text { (16) with } \quad \mu^{\prime}(\mathrm{L})=\mu \frac{\mathrm{L}}{\mathrm{L}+\lambda}
$$

This result indicates that the apparent mobility $\mu$ ' should be gate length dependent in quasi ballistic device, according to (17). This dependency has been confirmed by Monte Carlo simulations ${ }^{38}$. Note that this apparent mobility corresponds to the mobility extracted from experiments, using the usual Drift Diffusion formula.

Finally, let us note that the Lundstrom model, as recognized by the author himself ${ }^{63}$, cannot be considered as a complete model. Indeed, the evaluation of the kT layer length requires knowing a priori the potential profile, which cannot be computed within this approach.

When drift diffusion equation applies, in long channel device, the potential profile can be analytically derived using the channel gradual approximation, leading to the following expression of the kT layer length: 


$$
\mathrm{L}_{\mathrm{kT}}=\mathrm{L} \frac{2 \mathrm{kT}}{\mathrm{e}\left(\mathrm{V}_{\mathrm{dsat}}\right)}=\mathrm{L} \frac{2 \mathrm{kT}}{\mathrm{e}\left(\mathrm{V}_{\mathrm{g}}-\mathrm{V}_{\mathrm{T}}\right)}
$$

As shown in figure 6, this equation is indeed the expression needed to match exactly the well-known long channel drift diffusion equation and the quasi-ballistic equation (11) in saturation regime. In shorter device, for compact model application, the kT layer is usually estimated using empirical formula calibrated on simulation results. In reference 64 for instance, the following expression has been used:

$$
\mathrm{L}_{\mathrm{kT}} \approx \mathrm{L}\left(\beta \frac{\mathrm{kT}}{\mathrm{e}\left(\mathrm{V}_{\mathrm{dsat}}\right)}\right)^{\alpha}
$$

where $\alpha$ is a parameter deduced from the exact shape of the potential profile $(\alpha \sim 0.7)$. The $\beta$ parameter takes into account degeneracy effects, and "should be somewhat greater than 1 ,64.

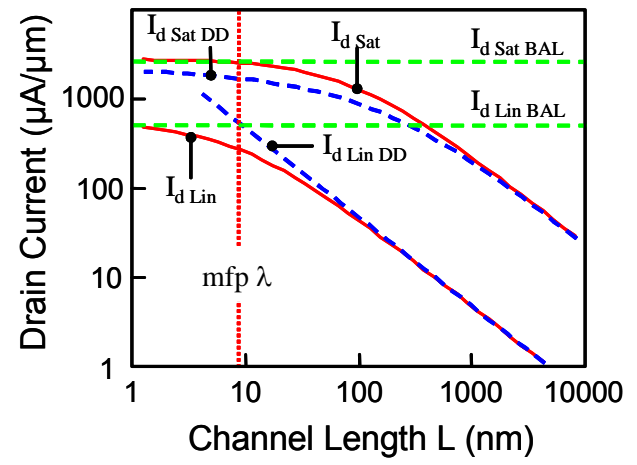

Figure 6 : Id - L curves (at same voltage, and constant mean free path) computed in linear $\left(\mathrm{V}_{\mathrm{ds}}=10 \mathrm{mV}\right)$ as well in saturation regime $\left(\mathrm{V}_{\mathrm{ds}}=1 \mathrm{~V}\right)$ using the Natori Lundstrom approach $\left(\operatorname{Id}_{\mathrm{Lin}}\right.$ and $\left.\operatorname{Id}_{\text {Sat }}\right)$ and the drift diffusion approach $\left(\operatorname{Id}_{\mathrm{Lin} D D}\right.$ and $\left.\mathrm{Id}_{\text {Sat DD }}\right)$, accounting for saturation velocity. The ballistic limit $\left(\operatorname{Id}_{\mathrm{Lin} B A L}\right.$ and $\operatorname{Id}_{\text {Sat }}$ BAL) is also shown for comparison. $\left(\mu=200 \mathrm{~cm}^{2} \mathrm{~V}^{-1} \mathrm{~s}^{-1}, \mathrm{~V}_{\text {inj }}=1.210^{5} \mathrm{~m} / \mathrm{s}, \mathrm{N}_{\text {inv }}=1.4510^{13} \mathrm{~cm}^{-2}, \mathrm{~L}_{\mathrm{kT}}\right.$ has been estimated using equation (18))

The Natori Lundstrom formalism, with or without minor improvements, has become extremely popular in the last ten years. It has been considered as the state of the art of the understanding of transport in advanced MOSFETs, to analyze experiments 48495051525354 555657 , improve compact models ${ }^{58596064}$ as well as to investigate scaling trends ${ }^{6162}$. The validity and limits of this approach are discussed in the next section. 


\section{Beyond the Natori-Lundstrom model}

\subsection{Theoretical foundations of the Natori Lundstrom model: the quasi ballistic drift-diffusion theory}

Due to the empirical nature of the arguments introducing it and despite quantitative validation by Monte Carlo simulations ${ }^{39}{ }^{42}$, the concept of kT layer has raised skepticism among the device modeling community. In order to achieve a better understanding of the kT layer concept, its theoretical basis has been investigated in reference 65 . Considering one dimension in space, assuming non degenerated statistics, one single isotropic band, and treating the collision integral by a simple "relaxation length" approximations, its has been shown that the Boltzmann Transport Equation can be reduced to a simpler formalism, sometimes referred to as the "Quasi Ballistic drift diffusion" formalism. Within these approximations, the solution of the BTE has shown that the distribution function $f(x, v)$ could be artificially split into two functions, one for positive velocity, one for negative velocity, both of them having a Maxwellian (thermal) shape, given by:

$$
\mathrm{f}^{ \pm}\left(\mathrm{x}, \mathrm{v}_{\mathrm{x}}\right)=2 \sqrt{\frac{\mathrm{m}}{2 \pi \mathrm{kT}}} \mathrm{n}^{ \pm}(\mathrm{x}) \exp \left(-\frac{\mathrm{m} \mathrm{v}_{\mathrm{x}}{ }^{2}}{2 \mathrm{kT}}\right)
$$

where $\mathrm{n}^{+}$(resp. $\mathrm{n}^{-}$) are the concentration of carriers flowing from source to drain (resp. from drain to source). In addition, these concentrations have been found to obey the following conservation equations:

$$
\begin{gathered}
\frac{\mathrm{d} \mathrm{n}^{-}}{\mathrm{dx}}+\frac{\mathrm{n}^{-}}{\mathrm{kT}} \frac{\mathrm{d} \mathrm{U}}{\mathrm{dx}}=\frac{\mathrm{n}^{-}-\mathrm{n}^{+}}{\lambda} \\
\Phi^{+}(\mathrm{x})-\Phi^{-}(\mathrm{x})=\left(\mathrm{n}^{+}(\mathrm{x})-\mathrm{n}^{-}(\mathrm{x})\right) \mathrm{v}_{\mathrm{th}}=\Phi
\end{gathered}
$$

where $\Phi$ is the net flux of carriers, independent of the position $\mathrm{x}$. This approach, approximation of semi classical transport in the framework of the relaxation length approximation, includes the impact of both isotropic scattering and arbitrary field, and constitutes thus a more general formalism than the kT layer model. It has been known in fact for a long time ${ }^{66} 67$, but its connection with the kT layer concept has been clarified only recently ${ }^{65}$.

Indeed, an expression of the backscattering coefficient can be derived using the quasi ballistic drift diffusion model, assuming a linear potential profile $\mathrm{V}(\mathrm{x})=-\mathrm{qFx}$ ( with $\mathrm{F}<$ 0 ) between source and drain. In order to discriminate backscattered carriers emitted by the source from carriers emitted from the drain, the drain reservoir has been assumed in the calculation to only absorb carriers, leading to the boundary condition $\mathrm{n}^{-}(\mathrm{L})=0$. As the calculations are performed non-self consistently, this procedure does not impact the expression of $\mathrm{r}$, as demonstrated in 65 .

Solving equations (21) and (22) leads to the following expression of the backscattering coefficient $\mathrm{r}$ :

$$
\mathrm{r}=\frac{\mathrm{j}^{-}(0)}{\mathrm{j}^{+}(0)}=\frac{\mathrm{v}_{\mathrm{th}} \mathrm{n}^{-}(0)}{\mathrm{v}_{\mathrm{th}} \mathrm{n}^{+}(0)}=\frac{\mathrm{L}_{\mathrm{kT}}(1-\beta)}{\lambda+\mathrm{L}_{\mathrm{kT}}(1-\beta)}
$$


with $\beta=\exp \left(-\mathrm{L} / \mathrm{L}_{\mathrm{kT}}\right)$, and $\mathrm{L}_{\mathrm{kT}}=\mathrm{kT} / \mathrm{q}|\mathrm{F}|$. This simple equation of $\mathrm{r}$ nicely tends to the Lundstrom formula at both low field (Eq. 13) and high field (Eq. 14) conditions.

Let us examine in more details the implications of this "quasi ballistic drift diffusion model". First of all, starting from equation (21), multiplying by $\mathrm{v}_{\mathrm{th}}$, and introducing the total carrier concentration $n$, equal to:

$$
\mathrm{n}(\mathrm{x})=\mathrm{n}^{+}(\mathrm{x})+\mathrm{n}^{-}(\mathrm{x})
$$

the net flux of carriers $\Phi$ can be re-written as :

$$
\Phi=-D \frac{d n}{d x}-2 n^{-} \mu E
$$

where $\mathrm{D}=\lambda \mathrm{v}_{\text {th }}$ and $\mu=\mathrm{e} \mathrm{D} / \mathrm{kT}$. Using equation (15) and Einstein relation, $\mu$ and D effectively correspond to the conventional long channel low field mobility and diffusion coefficient. Moreover, $\mathrm{n}^{-}$in equation (25) can be expressed as a function of $\mathrm{n}$ and $\Phi$, using both equations (22) and (24), leading to:

$$
\Phi=-D^{\prime} \frac{\mathrm{d} \mathrm{n}}{\mathrm{dx}}-\mathrm{n} \mu^{\prime} \mathrm{E}
$$

where

$$
\mu^{\prime}=\frac{\mu}{1+\mu \mathrm{E} / \mathrm{v}_{\mathrm{th}}}
$$

and $\mu^{\prime}=\mathrm{e} \mathrm{D}^{\prime} / \mathrm{kT}$. Equations (26) and (27) suggest that one of the consequences of the quasi ballistic drift diffusion model, compared to the conventional drift diffusion approach, is the introduction of a longitudinal field dependent mobility. In addition, equation (27) limits the average velocity to the maximum value of $v_{t h}$. In this approach, this modification is a direct consequence of the constant mean free path and relaxation length approximations, which force the positive and negative distribution functions to keep a Maxwellian shape along $\mathrm{x}$. Thus positive and negative carriers move with an average velocity equal to the thermal velocity. Ironically, conventional drift diffusion already includes longitudinal field dependency to the mobility, in an attempt to account for saturation velocity. As already pointed out by Lundstrom et al. ${ }^{78}$, as in Silicon the thermal velocity and the saturation velocity have similar values, it explains a posteriori why a simple drift diffusion model can qualitatively emulate the ballistic limit.

However, it should be mentioned that boundary conditions have to be applied with care when using the quasi ballistic drift diffusion model. Indeed, as discussed in 65, and contrary to what has been done in previous works such as 60 , in the quasi ballistic model, boundary conditions are applied on $\mathrm{n}^{+}(0)$ and $\mathrm{n}^{-}(0)$ and not on $\mathrm{n}(0)$ and $\mathrm{n}(\mathrm{L})$, as in a conventional drift diffusion model. These quasi ballistic boundaries conditions make non obvious the direct use of equations (26) and (27). Note that if conventional drift diffusion boundary conditions were used instead of the correct one, the impact of quasi-ballistic transport particularly in low field condition would be erroneous. Indeed, as $\mu \mathrm{E}<<v_{\text {th }}$ in low field condition, this approach would lead to the conclusion that the apparent mobility in the quasi ballistic regime remains equal to the long channel mobility $\mu$, even in a full ballistic channel. This is obviously not the correct result, given instead by equation (17). Finally, let us note that equation (27) constitutes one of the main limitations of the quasi ballistic drift diffusion model, as it suppresses any possibility of velocity overshoot. 
Indeed, as it will be more clearly shown in the next section, velocity profiles obtained by Monte Carlo simulations usually largely exceed the thermal velocity. As the potential profile should be computed self consistently with the motion of carriers (thus the velocity profiles), it induces that the potential profile, and thus the $\mathrm{L}_{\mathrm{kT}}$ value computed self consistently, is indeed erroneous in the quasi ballistic drift diffusion approach.

The quasi ballistic drift diffusion model approach ${ }^{65} 6667$ can take different forms in the literature. As already mentioned, it is equivalent to the Lundstrom backscattering coefficient $\operatorname{model}^{78}$. The equivalence with the Gildenblat flux model ${ }^{58} 59$ can also be proved.

\subsection{Comparison with Monte Carlo simulations: results and discussion}

The validity of the Lundstrom formula of backscattering have been investigated by Monte Carlo simulations in several contributions 38394042434445 . This section summarizes the conclusions obtained in one of the most recent works ${ }^{42}$.

In this paper, mobility $\mu$ and backscattering coefficient $r$ have been computed using the Monte Carlo (MC) method, in simplified structures. These template devices are 1D in real space, and $2 \mathrm{D}$ in the momentum space. The effective mass approximation has been used, assuming a spherical band (with an effective mass equal to $\mathrm{m}_{0}$ ). Only phonon scattering has been taken into account, featuring one acoustic phonon mode and one optical phonon mode (of energy $35 \mathrm{meV}$ ). Simulations have been performed in a "frozen field" mode, i.e. without computing the potential energy profile self consistently with the motion of carriers. These simplifications have only been made in an attempt to simplify the analysis and interpretation of results. The mobility has been computed at low field condition in an infinitely long structure, by imposing periodic boundary conditions. In addition, backscattering coefficient has been simulated in a finite structure of length $\mathrm{L}$, where the right contact (drain-like) has been artificially "switched off", i.e. does not inject carriers into the structure, as explained in the last section. In term of MC simulation, it means that particles are only injected by the left contact (source like), assumed to be in equilibrium condition, and absorbed by the drain. This unphysical boundary condition makes easier the extraction of the backscattering coefficient, especially at low field condition, as the flux of carriers coming back to the source have been necessarily emitted by the same contact (and not by the drain). While the Potential Energy profile has been taken equal to zero at low field condition, both a linear and parabolic Potential Energy profiles have been considered at high field condition.

The backscattering coefficient $r$ extracted at low field condition has been plotted versus the structure length $\mathrm{L}$ in figure 7 . It turns out that the MC results can be nicely fitted by equation $r=L /(L+\lambda)$ (dotted lines in figure 7), provided that the mean free path $\lambda$ has been used as a fitting parameter. The low field mean free path extracted by this procedure will be referred to as $\lambda_{0}$ in the following. 


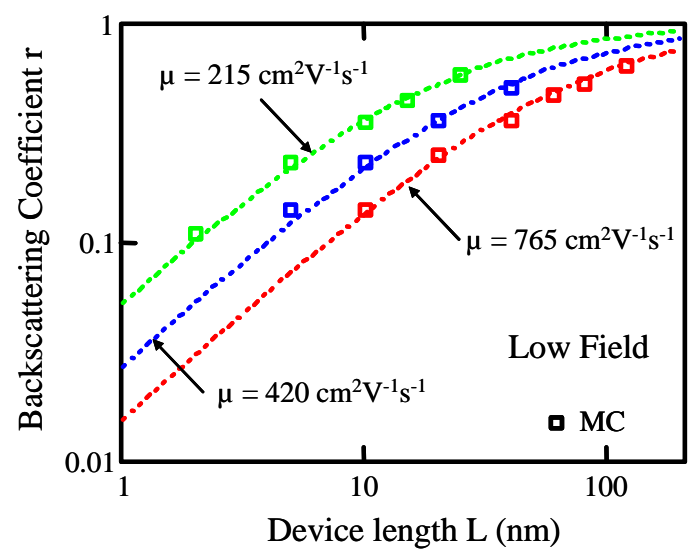

Figure 7 : Low Field backscattering coefficient $\mathrm{r}_{\mathrm{LF}}$ versus device length $\mathrm{L}$, extracted from $1 \mathrm{D}$ non self consistent Monte Carlo simulation in low field condition, featuring different acoustic phonon coupling constants, i.e. different mobilities. The coupling constant for optical phonons has been kept constant and equal to $2.10^{12} \mathrm{eV} / \mathrm{m}$.

A similar procedure has been applied to the high field results: $r$ has been plotted as a function of the kT layer length $\mathrm{L}_{\mathrm{kT}}$, as shown in figure 8. Again, these results can be accurately reproduced by $\mathrm{r}=\mathrm{L}_{\mathrm{kT}} /\left(\mathrm{L}_{\mathrm{kT}}+\lambda\right)$ using the mean free path (referred to as $\lambda_{\mathrm{F}}$ in the following) as a fitting parameter.

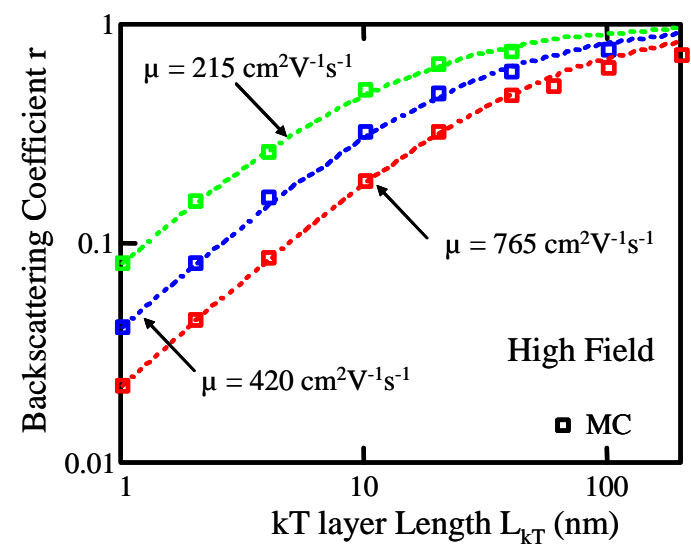

Figure 8: High Field backscattering coefficient $r_{\mathrm{HF}}$ versus $k T$ layer length $\mathrm{L}_{\mathrm{kT}}$. The device length is $\mathrm{L}=10 \mathrm{~L}_{\mathrm{kT}}$. The $\mathrm{L}_{\mathrm{kT}}$ range corresponds to electric fields from $2.6 \mathrm{kV} / \mathrm{cm}$ to $260 \mathrm{kV} / \mathrm{cm}$. Other parameters are the same than in Figure 5 . 
Both $\lambda_{0}$ and $\lambda_{\mathrm{F}}$ have been plotted in figure 9 , as a function of the mobility also computed by MC simulations in the same but infinitely long simple structure. According to the Lundstrom theory, $\lambda_{0}$ and $\lambda_{\mathrm{F}}$ should be equal and given by equation (15), also plotted for comparison in dotted line in figure 9. While $\lambda_{0}$ has been found in qualitative good agreement with the prediction of equation (15), $\lambda_{\mathrm{F}}$ however appears significantly lower.

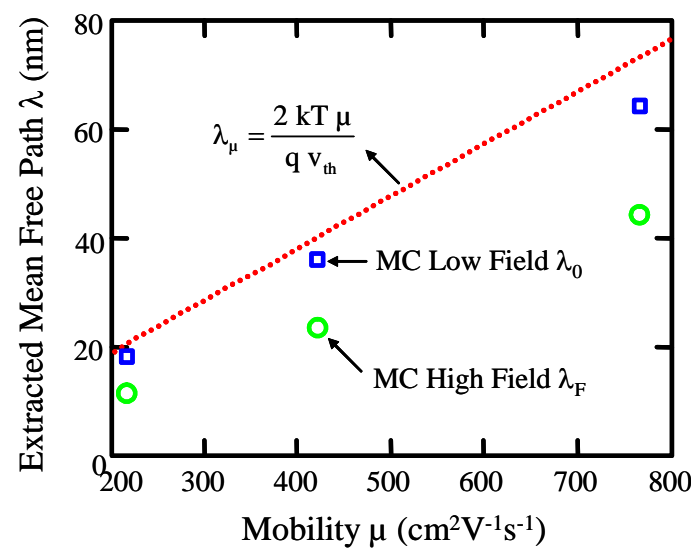

Figure 9: Extracted mean free path in low field (square) and high field (circle) conditions, plotted versus low field mobility. Equation (15) is also shown in dotted line as reference.

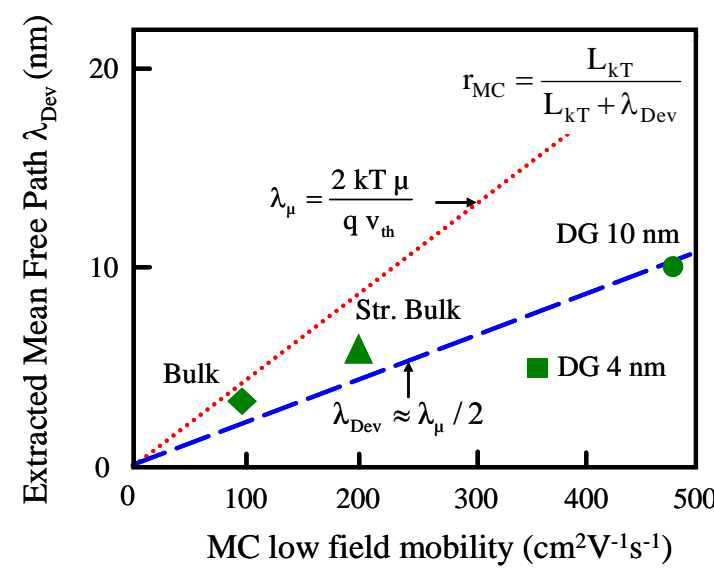

Figure 10: Extracted mean free path in high field condition extracted from device Monte Carlo simulations (symbol) plotted versus MC long channel low field mobility. Equation (3) is also shown in dotted line as reference.

Similar comparisons have also been performed on more realistic device structure (see figure 10) (2D in real space, including all the relevant scattering mechanisms: phonons, impurities, surface roughness and body thickness fluctuations in the case of ultra thin body devices). All devices are $25 \mathrm{~nm}$ long, "Bulk" refers to unstrained bulk transistor, "Str. Bulk" to a similar device with ideal biaxially strained channel, DG to undopded double gate devices with body thickness of $10 \mathrm{~nm}$ and $4 \mathrm{~nm}$. Device mobility has been 
computed using the same model, but in an infinitely long inversion layer. It turns out that even using a more sophisticated model, the extracted mean free path in high field condition appears qualitatively proportional to the corresponding long channel low field mobility, however with a lower slope than expected according to Eq. (15).

In conclusion, the Lundstrom model for backscattering coefficient may appear qualitatively correct, especially in low field condition, but also in high field, provided to use the mean free path as a fitting parameter. This extracted mean free path has been found shorter that the equilibrium mean free path predicted by the Lundstrom theory.

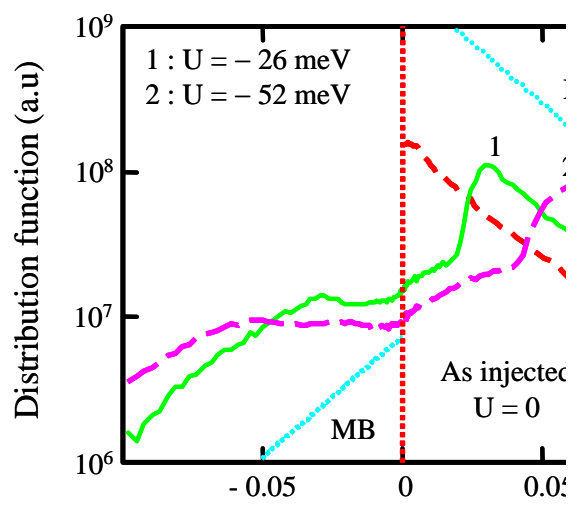

Figure 11: Distribution functions as injected (dotted line) and at different point of the template structure, close to the emitting source, as a function of the energy $E_{x}$ in the transport direction. The thermal Maxwellian shapes are also indicated for comparison.

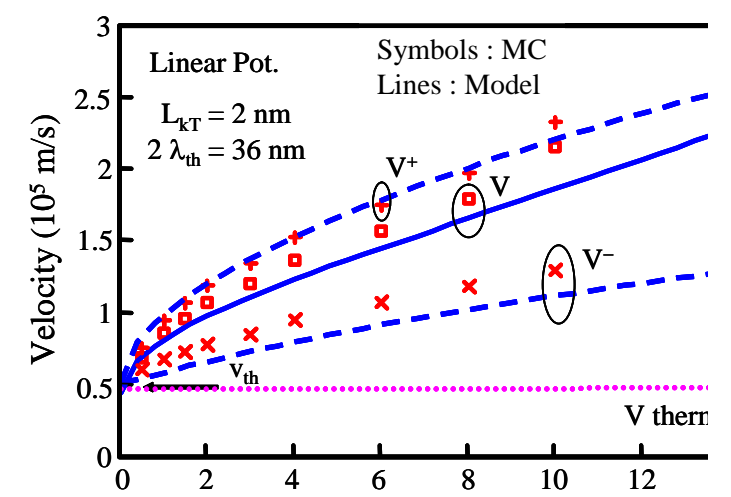

Figure 12: Positive $\mathrm{V}^{+}$, negative $\mathrm{V}^{-}$and average $\mathrm{V}$ Monte Carlo Velocity profile (symbols) versus distance in a template 1D structure with linear profile potential (in high field conditions) and absorbing drain. Results obtained by the analytical model proposed in 69 (dotted line) are shown for comparison. $\mathrm{V}_{\text {thermal }}$ indicates the velocity profile obtained using the quasi ballistic drift diffusion model.

The detailed understanding of this discrepancy at high field is however more complex than it may seem. This point has been investigated in more detailed in ref. 69, underlying the role of heated distribution functions on quasi ballistic transport. Indeed, as explained in section 3.1, the kT layer approach approximates the carrier distribution function $\mathrm{f}$ by two equilibrium distribution functions (one for positive, one for negative velocity), 
following equations (20). As shown in figure 11, this assumption is of course in disagreement with Monte Carlo simulations, which however predicts a distribution function closer to a pure ballistic one. This limitation of the kT layer approach is particularly penalizing to model the velocity profiles. Indeed, according the thermal distribution functions given by equations (20), the carrier velocity can never exceed the thermal velocity. This is obviously not true, in particular in the high field region close to the drain (see an example Fig. 12).

In 69, the balance equations of transport in the relaxation length approximation has been generalized to any kind of distributions functions, and solved for approximated distribution functions inspired by Monte Carlo results. This approach has lead to backscattering coefficient in much better agreement with simulations, without any artificial reduction of the mean free path. However, efforts are still needed to turn this kind of approaches into a complete compact model.

\section{Electrical Characterization of MOSFETs in the Quasi Ballistic Regime}

\subsection{Introduction \& State of the art}

The analytical modeling of quasi ballistic transport, reviewed in the previous sections, has raised of course several interrogations from an experimental point of view:

- first of all, is there an experimental way to validate or not the concepts of Ballistic, Quasi Ballistic Transport and formula for backscattering coefficients?

- assuming that the quasi ballistic theory applies, how to improve parameter extraction procedures, which usually rely on the "old fashion" drift diffusion equations?

- $\quad$ and more specifically how to monitor the Ballistic Enhancement Ratio, possible "booster" of CMOS performances?

In previous works, the quasi ballistic theory of transport has been implicitly assumed as valid, and most of the attention has been focused on the two last questions. In particular, several works have tried to define a suitable parameter extraction procedure to measure the backscattering coefficient $r$ or the ballistic ratio, usually at high field conditions ${ }^{4849} 50$

515253 . In addition to the usual experimental difficulties (series resistance extractions, capacitance measurements ...), most of these techniques have required an a priori knowledge of either the ballistic limit or the injection velocity. As mentioned before, the available analytical approaches to estimate them are not very accurate, leading, as explained in ref. 38, to significant errors in parameter extractions. In addition, it was never easy to benchmark results obtained in different works, as the extracted data significantly depends on the model used to estimate the ballistic limit or the injection velocity.

Moreover, other works have tried to determine some experimental evidence of the quasi ballistic nature of transport in advanced MOSFETs 54555657 . These works have raised several relevant doubts and questioning, not about the theory itself, but rather about the applicability of the theory to advanced MOSFETs. The methodology and results of one of these works are reported in the following section. 


\subsection{Principle of backscattering coefficient extraction in the linear regime}

Following reference 72 and equations (16) and (17), the quasi-ballistic drain current of a MOS transistor in linear operation can readily be equated to ${ }^{73}$ :

$$
I_{d}=(1-r) \frac{W}{L} \mu_{b a l} Q_{i} V_{d}=r \frac{W}{L} \mu_{d d} Q_{i} V_{d}=\frac{W}{L} \mu_{\exp } Q_{i} V_{d}
$$

where $\mathrm{Q}_{\mathrm{i}}$ is the inversion charge, $\mathrm{W}$ and $\mathrm{L}$ the gate width and length, $\mathrm{V}_{\mathrm{d}}$ the drain voltage, $\mu_{\text {bal }}$ the "ballistic" mobility, $\mu_{\mathrm{dd}}$ the drift-diffusion one (i.e. the low field long channel mobility) whereas $\mu_{\exp }$ stands for the experimental or apparent mobility to be measured from drain current, by using Eq. 28. The ballistic mobility $\mu_{\text {bal }}$ can be derived from equation (28) after considering the drain current expression in the ballistic limit equations (1)-(5), considering only one subband, yielding ${ }^{745}$,

$$
\mu_{\text {bal }}=\frac{\mathrm{e}_{\text {th }} L}{2 \mathrm{kT}} \cdot \frac{\mathrm{F}_{-1 / 2}\left(\eta_{\mathrm{F}}\right)}{\mathrm{F}_{0}\left(\eta_{\mathrm{F}}\right)}
$$

where $\mathrm{v}_{\text {th }}$ is the thermal velocity at the virtual source, $\mathrm{F}_{-1 / 2}$ and $\mathrm{F}_{0}$ are the Fermi-Dirac functions, with $\eta_{\mathrm{F}}$ being the reduced Fermi level $\left(\mathrm{E}_{0}-\mathrm{E}_{\mathrm{F}}\right) / \mathrm{kT}$. In the Boltzmann statistics limit, the ratio $F_{-1 / 2}\left(\eta_{F}\right) / F_{0}\left(\eta_{F}\right)$, also called the degeneracy factor $\operatorname{DF}\left(\eta_{F}\right)$, reduces to one, recovering Shur's $\mu_{\text {bal }}$ expression ${ }^{74}$.

Note that the degeneracy factor can be well approximated as $\operatorname{DF}\left(\mathrm{Q}_{\mathrm{i}}\right) \approx 1 /\left(1+\mathrm{Q}_{\mathrm{i}} / \mathrm{Q}_{\mathrm{c}}\right)$ for the single subband case in the quantum limit $\left(Q_{c}\right.$ being a constant close to $2.10^{13} \mathrm{q} / \mathrm{cm}^{2}$ for silicon). Figure 13 shows a simulation of the DF function for (100) silicon when considering only the fundamental subband, which validates the previous empirical relationship.

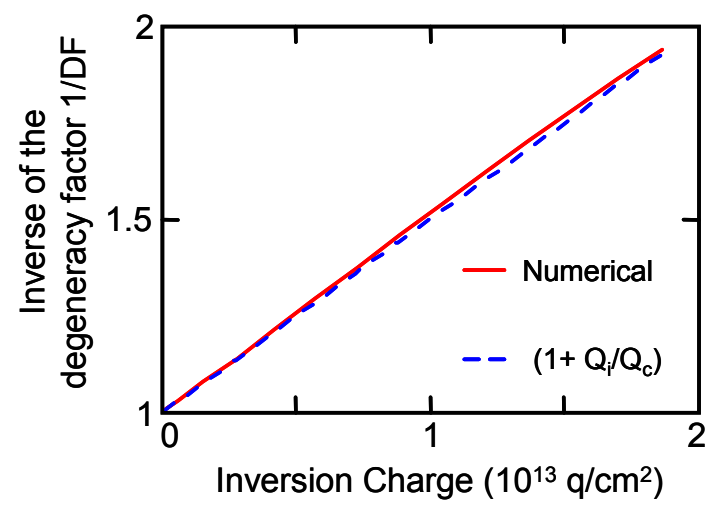

Figure 13. Variation of 1/DF with inversion charge $Q_{i}$ for the fundamental 2D subband of (100) silicon : exact (solid line) and linear approximation (dashed line). Parameters: gate oxide thickness $t_{\mathrm{ox}}=1.6 \mathrm{~nm}$, $\mathrm{Q}_{\mathrm{c}}=2 \cdot 10^{13} \mathrm{q} / \mathrm{cm}^{2}$.

Eliminating the backscattering coefficient in Eq. (28) enables to recover the Matthiessenrule-like expression for $\mu_{\exp }{ }^{74}$ :

$$
\frac{1}{\mu_{\text {exp }}}=\frac{1}{\mu_{\text {bal }}}+\frac{1}{\mu_{\text {dd }}}
$$

It is now straightforward to derive the backscattering coefficient from Eq. (28) as : 


$$
r=1-\frac{\mu_{\text {exp }}}{\mu_{\text {bal }}}
$$

\subsection{Results and discussion}

The above method has been used for the extraction of the backscattering coefficient and drift-diffusion mobility in advanced CMOS devices fabricated by STMicroelectronics (Crolles). Bulk and FD-SOI nMOS devices were tested. The bulk devices are representative of a $65 \mathrm{~nm}$ CMOS technology featuring a doped channel $\left(\approx 10^{17} / \mathrm{cm}^{3}\right)$ with halos, SiON gate oxide $(\mathrm{CET}=2.2 \mathrm{~nm})$ and polysilicon gate. For the FD-SOI technology, the nMOS devices were made on $300 \mathrm{~mm}<100>$ UNIBOND $^{\mathrm{TM}}$ SOI wafers with a BOX of $145 \mathrm{~nm}$. The SOI films were thinned down by thermal oxidation and wet etched to achieve a final thickness around $10 \mathrm{~nm}$ under the gate at the end of the process. After STI isolation, a HfSiON dielectric of approximately $2.5 \mathrm{~nm}$ was deposited. A TiN of 10nm and a poly-Si layer of $100 \mathrm{~nm}$ were deposited for gate fabrication. A $193 \mathrm{~nm}$ lithography combined with trimming was performed to achieve reduced gate dimensions. The minimum gate length dimension measured on the wafers is around $40 \mathrm{~nm}$. After an offset spacer of $10 \mathrm{~nm}$ realization, a selective epitaxy of $10 \mathrm{~nm}$ was performed in order to reduce access resistance and to facilitate NiSi S/D salicidation. Raised extensions were implanted. To finish, a Dshape spacer, S/D implantation and salicidation were realized. The device channel was left undoped.

The static parameter extraction was then performed in linear operation regime $\left(\mathrm{V}_{\mathrm{d}}=\right.$ $20 \mathrm{mV}$ ) on transistor arrays with common source and gate for various gate lengths $(40 \mathrm{~nm}$ to $10 \mu \mathrm{m}$ ) using the $\mathrm{Y}=\mathrm{I}_{\mathrm{d}} / \mathrm{g}_{\mathrm{m}}{ }^{1 / 2}$ function method $^{76}$, allowing the elimination of series resistance effect, the extraction of threshold voltage and of the low field mobility $\mu_{0}$ for each gate length. The effective gate length and the gate oxide capacitance $C_{o x}$ were extracted from gate-to-channel capacitance measurements ${ }^{77}$.

The low field mobility $\mu_{\exp }$ was extracted as a function of channel length for the various tested nMOS devices (see Figure 14). Note that in all cases, a strong degradation of the mobility, by about a factor 2 , is observed as the channel length is reduced below $100 \mathrm{~nm}$ for both technologies. The drift-diffusion contribution of the mobility $\mu_{\mathrm{dd}}$ was then evaluated after subtracting the ballistic mobility contribution using Eq. 30. The ballistic mobility $\mu_{\text {bal }}$ has been calculated using Eq. 29, assuming that the injection velocity is equal to the thermal velocity. This is a reasonable assumption since the low field mobility is experimentally extracted near threshold voltage, i.e. at low enough inversion charge. Figure 14 demonstrates without any ambiguity that the drift-diffusion mobility $\mu_{\mathrm{dd}}$ is strongly degraded below $100 \mathrm{~nm}$, and that the ballistic effects cannot explain here the huge apparent mobility reduction obtained on both technologies. This mobility behavior is a general feature of both bulk and thin film devices regardless of their channel doping as was already observed in gate-all-around (GAA) and bulk MOS structures ${ }^{5478} 79$. This could be interpreted as an increasing contribution of scattering mechanisms in shorter devices (below $70-80 \mathrm{~nm}$ ), possibly due to neutral defects. These defects may originate from source-drain implantation-induced $\mathrm{Si}$ interstitials in undoped film and halo extra doping in bulk architectures ${ }^{57}$. 


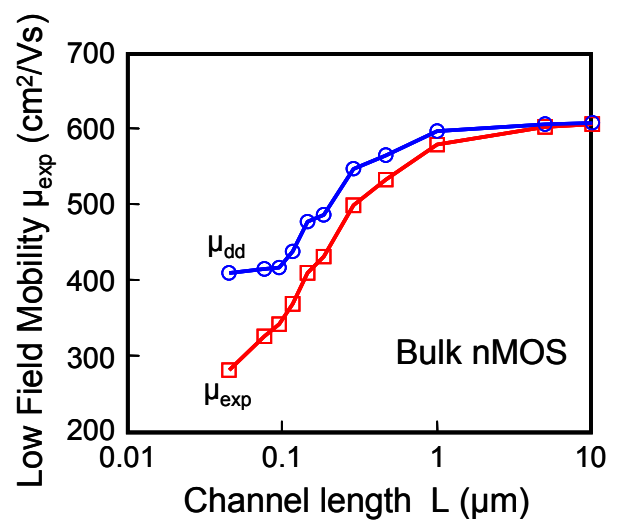

(a)

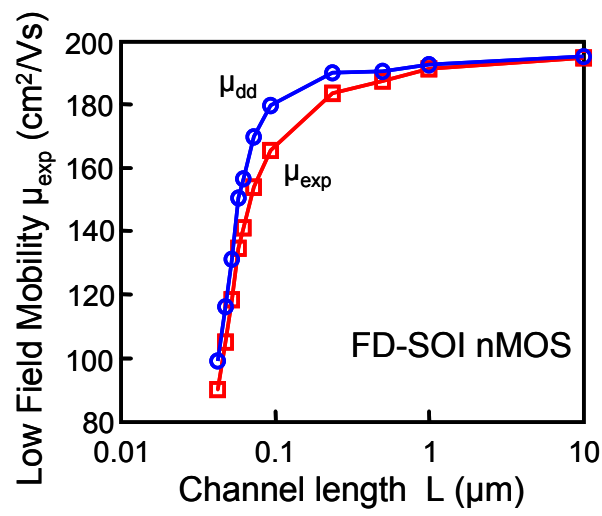

(b)

Figure 14. Variation of experimental low field mobility $\mu_{\exp }$ with channel length $L$ as obtained on bulk (a) and FD-SOI devices (b). The drift-diffusion mobility $\mu_{\mathrm{dd}}$ obtained after ballistic effect correction is also shown.

Finally, the backscattering coefficient $r$ has been extracted using Eq. 31 as a function of gate length (Figure 14). As expected, $\mathrm{r}$ is decreasing at small gate length down to about 0.70 and 0.86 , which indicates that the ballistic ratio in ohmic regime (i.e $1-r$ ) in these devices reaches at most $30 \%$ and $14 \%$ over $40-50 \mathrm{~nm}$ gate length range, for bulk and FDSOI devices, respectively.

The larger ballistic rate observed in the bulk devices can be justified by the higher mobility values over the whole gate length range, despite the channel and halo higher doping levels. This feature clearly indicates that the quality of undoped thin film structures is not yet optimized compared to well mature bulk technologies in order to benefit from full ballistic effect.

The different behavior of $\mu_{\mathrm{dd}}$ and $\mathrm{r}$ for bulk and FD-SOI devices at small channel length, could be attributed to the fact that, for bulk devices, halos are merging below $0.1 \mu \mathrm{m}$, yielding a nearly constant channel doping. In consequences, $\mu_{\mathrm{dd}}$ in bulk devices is becoming constant at small gate length. In contrast, for FD-SOI devices, $\mu_{\mathrm{dd}}$ is still degraded at small lengths because the concentration of the S-D implantation-induced defects should increase as getting closer to source and drain junctions.

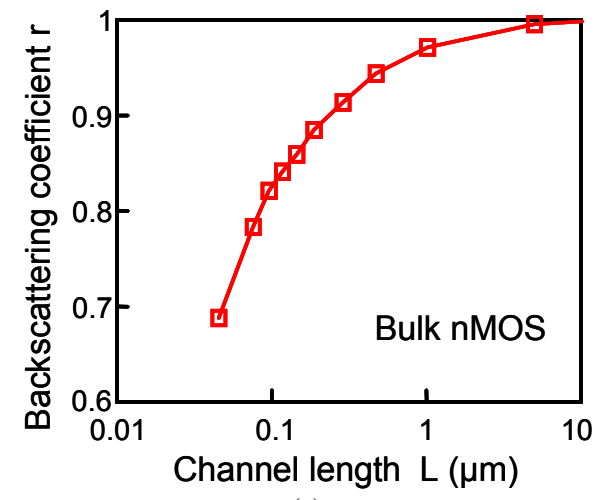

(a)

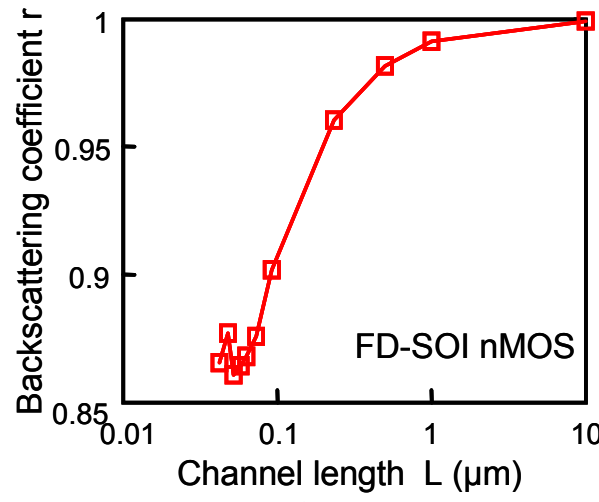

(b)

Figure 15. Variation of backscattering coefficient $r$ with channel length L for Bulk (a) and FD-SOI devices (b). 
This mobility degradation as a function of gate length has recently been analyzed in a statistical way and it has been found, as illustrated in Fig. 16 for FD-SOI devices, that the low field mobility can always be expressed as ${ }^{79}$,

$$
\frac{1}{\mu_{0}}=\frac{1}{\mu_{\mathrm{dd}}}+\frac{\alpha_{\mu}}{\mathrm{L}}
$$

where $\mu_{\mathrm{dd}}$ is the low field long channel mobility and $\alpha_{\mu}$ a mobility degradation factor [nm.V.s $\left./ \mathrm{cm}^{2}\right]$. Actually, Eq. 32 has successfully been applied to a large panel of CMOS devices featuring bulk, FD-SOI, double gate or GAA architectures ${ }^{79}$. Interestingly, as can be seen from Fig. 17, a strong correlation exists between the maximum mobility (for long devices) and the degradation factor $\alpha_{\mu}$. The comparison of the experimental results given by equation (32) with Eqs 29 and 30 reveals that $\alpha_{\mu}$ has a minimum theoretical value, given by its ballistic limit $(2 \mathrm{kT} / \mathrm{q}) / \mathrm{v}_{\text {th }}$. (for Boltzmann's statistics). The data of Fig. 17 also indicate that this limit could only be reached on few devices, which feature a very high long channel mobility of $600 \mathrm{~cm}^{2} / \mathrm{Vs}$ (resp. $300 \mathrm{~cm}^{2} / \mathrm{Vs}$ ) for electrons (resp. holes).

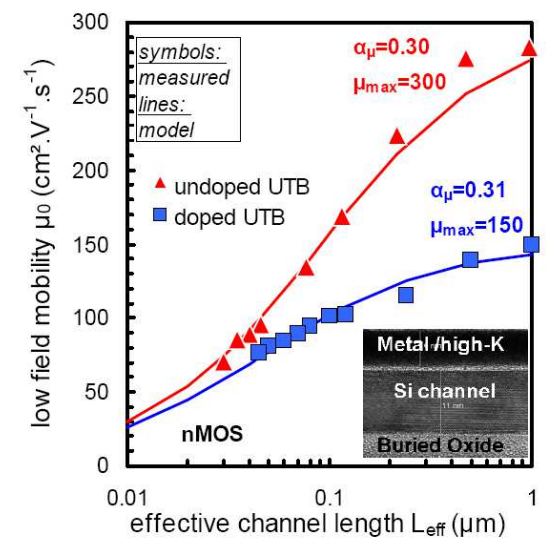

Figure 16. Comparison of electron mobility between undoped and doped ultra thin body (UTB) with high$\mathrm{K} / \mathrm{metal}$ gate stack (after Bidal et $\mathrm{al}^{79}$ ).

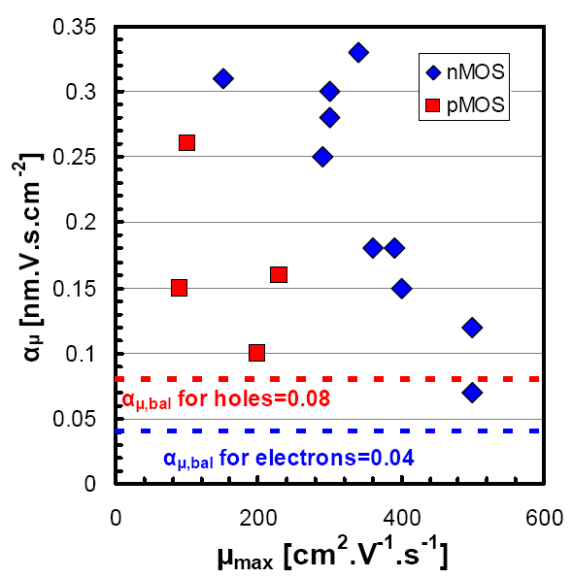

Figure 17. $\alpha_{\mu}$ as a function of $\mu_{\max }$ clearly showing no universal correlation between $\alpha_{\mu}$ and $\mu_{\max }$ (after Bidal et $\left.\mathrm{al}^{79}\right)$. 


\section{Conclusions}

Since the pioneering works of K. Natori ${ }^{17}$ in 1994, and then M. Lundstrom ${ }^{7}$ in 1997, the quasi ballistic regime of transport has become an extremely popular field of research in the area of MOSFET device physics. Interestingly, these researches have mostly been focused on the understanding of it, by means of analytical modeling and electrical characterization, since it was already naturally included in numerical sophisticated tools such as Boltzmann Transport Equation or Schrodinger Equation solvers.

Despite several ongoing controversies and unsolved issues ${ }^{44}{ }^{45}$, the main conclusions of these works have already become a new way of understanding performance enhancements of nano MOSFETs. For instance, the growing interest for high mobility channel devices ${ }^{30} 31$ is usually presented in terms of "mean free path" and "injection velocity" enhancements, two typical quasi ballistic concepts.

The quasi ballistic analytical models have been thus reviewed in this chapter.

First of all, the analytical modeling of MOSFET ballistic limit, following the approach of Natori has been presented. These theories have been used to investigate the "subband engineering ${ }^{26 ",}$, which consists in enhancing ballistic limit and thus improving injection efficiency, by raising 2D carrier gas confinement (introducing strain, film or field confinement, or new channels materials).

The critical impact of scattering on performances has also been discussed, presenting the "orthodox" Lundstrom's approach ${ }^{8}$, and its limitations. In particular, the connections between the high field kT layer backscattering theory and the old fashion "saturation velocity" have been clarified.

Despite progresses in analyzing the success and limitations of the backscattering theories, efforts are still to be made to achieve a simple formalism, able to fulfill the requirements of circuit oriented compact model, and accounting for ballistic limit, scatterings, velocity overshoot and self-consistency with electrostatic.

A closer look to experiments has also revealed an interesting feature of quasi ballistic transport: it is not clear, from an experimental perspective, if this phenomenon actually occurs or not. Indeed, measurements performed on several different technologies suggest a degradation of transport when reducing the gate length, making unlikely the existence of quasi ballistic regime. These degradations could possibly result from neutral defects ${ }^{54}$ generated by source and drain implantations. Again, more investigations are needed to confirm the existence of such defects, which challenge our understanding of advanced MOSFETs devices.

\section{Acknowledgments}

This work has been partially supported by the Nanosil Network of Excellence. The authors would like to thank colleagues for there contributions to the research activities presented here: Pierpaolo Palestri and Luca Selmi from Udine University (Italy), Antoine Cros, Frédéric Boeuf, Stéphane Monfray and Thomas Skotnicki from STMicroelectronics Crolles, and PhD students : Marlene Ferrier, Luca Lucci, Quentin Rafhay, Illias Pappas, Dominique Fleury and Gregory Bidal. 


\section{References}

1. ITRS 2003 Public Home Page, « Process Integration, Devices and Structures», http://www.itrs.net/

2. M. Lundstrom, "Fundamentals of Carrier Transport", 2nd Ed. Cambridge University Press, Cambridge UK, 2000

3. J. A. Cooper, D. F. Nelson, "High-field drift velocity of electrons at the $\mathrm{Si}_{-} \mathrm{SiO}_{2}$ interface as determined by a time-of-flight technique" J. Appl. Phys. 54 (3), p. 1445-56 (1983)

4. C. Jacoboni, L. Reggiani, "The Monte-Carlo method for the solution of charge transport in semiconductors with applications to covalent materials" Rev Mod Phys 55 (3) p. 645-705 (1983).

5. D. M. Caughey and R. E. Thomas, "Carrier Mobilities in Silicon Empirically Related to Doping and Field," Proc. IEEE 55, (12), p. 2192-2193 (1967).

6. S. E. Laux, R. G. Byrnes, "Semiconductor device simulation using generalized mobility models", IBM J. Res. Dev. 29(3) p.289-301 (1985)

7. M. Lundstrom «Elementary Scattering theory of the Si MOSFET »IEEE Electron Device Lett. 18 p. 361-363 (1997).

8. M. Lundstrom, Z. Ren, «Essential Physics of Carrier Transport in Nanoscale MOSFETs » IEEE Trans. on Electron Devices, 49 p. 133 - 141 (2002).

9. M. Fischetti et S. Laux., "Monte Carlo study of electron transport in silicon inversion layers", Phys. Rev. B, p. 2244 (1993).

10. L. Lucci, P. Palestri, D. Esseni, L. Selmi, "Multi-subband Monte Carlo modeling of nanoMOSFETs with strong vertical quantization and electron gas degeneration," in IEDM Tech. Dig. pp.631, 2005

11. L. Lucci, P. Palestri, D. Esseni, L. Bergagnini, L. Selmi; "Multisubband Monte Carlo Study of Transport, Quantization, and Electron-Gas Degeneration in Ultrathin SOI n-MOSFETs", IEEE Trans. Electron Devices, 54(5), pp. 1156-1164, May. 2007.

12. S.-M. Hong, C. Jungemann "A fully coupled scheme for a Boltzmann-Poisson equation solver based on a spherical harmonics expansion" J. Comp. Elec. 8(3-4) p. 225-241 (2009)

13. S. Datta, "Nanoscale device modeling: The Green's function method", Superlatt. Microstruct., 28, pp. 253-278, (2000)

14. M. Luisier, A. Schenk, "Atomistic Simulation of Nanowire Transistors", J. Comput. Theor. Nanosci. 5(6), p. 1031-1045 (2008)

15. S. Datta, «Electronic transport in mesoscopic Systems » Cambridge University Press, Cambridge UK, 1997.

16. R. Landauer, "Spatial Variation of Currents and Fields Due to Localized Scatterers in Metallic Conduction," IBM J. Res. Dev. 1, p. 233 (1957).

17. K. Natori, "Ballistic metal-oxide-semiconductor field effect transistor", J. Appl. Phys., 76 (8), p. 4879-4890, October 1994.

18. F Assad, Z Ren, D Vasileska, S Datta, M Lundstrom. "On the performance limits for Si MOSFETs: a theoretical study." IEEE Trans. Electron Devices 47(1) p.282 (2000)

19. M. Ferrier, R. Clerc, L. Lucci, Q. Rafhay, G. Pananakakis, G. Ghibaudo, F. Boeuf, T. Skotnicki., «Conventional Technological Boosters for Injection Velocity in Ultra Thin Body MOSFETs » IEEE Trans. on Nanotechnology, 6(6),p. 613 - 621 (2007)

20. Q. Rafhay, R. Clerc, M. Ferrier, G. Pananakakis and G. Ghibaudo, « Impact of Channel Orientation on Ballistic Current of nDGFETs with Alternative Channel Materials » SolidState Electronics, 52(4),p. 540-547 (2008)

21. M. Ferrier, R. Clerc, G. Ghibaudo, F. Boeuf, T. Skotnicki, “Analytical model for quantization on strained and unstrained bulk nMOSFET and its impact on quasi-ballistic current" SolidState Electronics, 50 p. 69-77 (2006)

22. M. Ferrier, R. Clerc, L. Lucci, G. Ghibaudo, A. Vandooren, F. Boeuf, T. Skotnicki, « Saturation Drain Current analytical modeling of Single Gate Fully Depleted SOI or SON 
MOSFETs in the Quasi Ballistic Regime of Transport », proc. of the IEEE International SOI Conference, USA, Niagara Falls, 2 - 5 October, 2006

23. M. Ferrier, R. Clerc, G. Pananakakis, G. Ghibaudo, F. Bœuf, T. Skotnicki, « Analytical Compact Model for Quantization in Undoped Double-Gate Metal Oxide Semiconductor Field Effect Transistors and Its Impact on Quasi-Ballistic Current », Jpn. J. Appl. Phys. 45 Part 1, No. 4B p 3088-3096 (2006)

24. Q. Rafhay, R. Clerc, G. Ghibaudo, G. Pananakakis, «Impact of source-to-drain tunnelling on the scalability of arbitrary oriented alternative channel material nMOSFETs », Solid-State Electronics, 52(10), p. 1474 - 1481 (2008)

25. Q. Rafhay, R. Clerc, G. Pananakakis and G. Ghibaudo, « Source-to-Drain vs. Band-to-Band Tunneling in Ultra-Scaled DG nMOSFETs with Alternative Channel Materials » Proc. SSDM 2008 pp. 36 - 37 (2008)

26. S. Takagi, "Re-examination of Subband Structure engineering in Ultra-Short Channel MOSFETs under Ballistic Carrier Transport" in Proc. VLSI 2003, pp. 115-116.

27. S. Takagi, T. Mizuno, T. Tezuka, N. Sugiyama, S. Nakaharai, T. Numata, J. Koga, K. Uchida, "Sub-band Structure engineering for Advanced CMOS channels", Solid-State Electronics, 49, pp. 684-694, 2005

28. A. Pethe, T. Krishnamohan, D. Kim, S. Oh, H. S. P. Wong, Y. Nishi, K. C. Saraswat, "Investigation of the performance limits of III-V Double-Gate n-MOSFETs", in IEDM Tech. Dig. pp. 605 (2005)

29. M. De Michielis, D. Esseni, F. Driussi, "Analytical Models for the Insight Into the Use of Alternative Channel Materials in Ballistic nano-MOSFETs" IEEE Trans. Electron Devices 54(1) p.115-123 (2007).

30. K. Saraswat, C. O. Chui, K. Donghyun, T. Krishnamohan, A. Pethe, "High mobility materials and novel device structures for high performance nanoscale MOSFETs," in IEDM Tech. Dig., pp. 659-662 (2006)

31. G. Dewey, M. K. Hudait, K. Lee, R. Pillarisetty, W. Rachmady, M. Radosavljevic, T. Rakshit, R. Chau, "Carrier Transport in High-Mobility III-V Quantum-Well Transistors and Performance Impact for High-Speed Low-Power Logic Applications" IEEE Electron Device Lett., 29, p. 1094 (2008)

32. S. Mudanai, L. F. Register, A. F. Tasch, and S. K. Banerjee, "Understanding the Effects of Wave Function Penetration on the Inversion Layer Capacitance of nMOSFETs" IEEE Electron Device Lett. 22, 145 (2001).

33. M. Yunus and A. Haque 'Wave function penetration effects on current-voltage characteristics of ballistic metal-oxide-semiconductor transistors', J. Appl. Phys. 93, p. 600 (2003)

34. Q. Rafhay, R. Clerc, J. Coignus, G. Pananakakis, G. Ghibaudo, « Dark Space, Quantum Capacitance and Inversion Capacitance in $\mathrm{Si}$, Ge, GaAs and $\mathrm{In}_{0.53} \mathrm{Ga}_{0.47} \mathrm{As}$ nMOS Capacitors », proc. of the ULIS conference pp. 33-37 (2010)

35. H. S. Pal, K. D. Cantley, S. S. Ahmed, M. S. Lundstrom, "Influence of Bandstructure and Channel Structure on the Inversion Layer Capacitance of Silicon and GaAs MOSFETs" IEEE Trans. Electron Devices, 55, (3), pp.904-908 (2008).

36. D. Jin, D. Kim, T. Kim, J. A. Del Alamo, "Quantum Capacitance in Scaled Down III-V FETs", in IEDM Tech. Dig. pp. 495-499, (2009).

37. K. D. Cantley, Y. Liu, H. S. Pal, T. Low, S. S. Ahmed, and M. S. Lundstrom "Performance Analysis of Ill-V Materials in a Double-Gate nano-MOSFET". IEDM Tech. Dig. pp. 113-116 (2007)

38. M. Zilli, P. Palestri, D. Esseni and L. Selmi, "On the experimental determination of channel back-scattering in nanoMOSFETs", IEDM Tech. Dig. p. 105. (2007)

39. P. Palestri, D. Esseni, S. Eminente, C. Fiegna, E. Sangiorgi and L.Selmi "Understanding Quasi-Ballistic Transport in Nano-MOSFETs: Part I - Scattering in the Channel and in the Drain," IEEE Trans. Electron Devices, 52, no. 12, pp. 2727 - 2735, Dec. 2005. 
40. S. Eminente, D. Esseni, P. Palestri, C. Fiegna, L. Selmi, E. Sangiorgi "Understanding QuasiBallistic Transport in Nano-MOSFETs: Part II - Technology Scaling Along the ITRS," IEEE Trans. Electron Devices, 52, no. 12, pp. 2736-2743, Dec. 2005.

41. J. Saint Martin, A. Bournel, and P. Dollfus, "On the ballistic transport in nanometer-scaled DG MOSFETs”, IEEE Trans. Electron Devices, 51, no. 7, pp. 1148-1155, Jul. 2004.

42. P. Palestri, R. Clerc, D. Esseni, L. Lucci and L. Selmi, "Multi-Subband-Monte-Carlo investigation of the mean free path and of the kT layer in degenerated quasi ballistic nanoMOSFETs," in IEDM Tech. Dig. pp. 945-949 (2006)

43. M. V. Fischetti, T. P. O'Regan, S. Narayanan, C. Sachs, S. Jin, J. Kim, Y. Zhang, "Theoretical Study of Some Physical Aspects of Electronic Transport in nMOSFETs at the 10-nm Gate-Length," IEEE Trans. Electron Devices, 54(9), pp. 2116 - 2136, Sept. 2007

44. M. V. Fischetti, S. Jin, T.-W. Tang, P. Asbeck, Y. Taur, S. E. Laux, M. Rodwell and N. Sano "Scaling MOSFETs to $10 \mathrm{~nm}$ : Coulomb effects, source starvation, and virtual source model" J. Comp. Elec., 8(2), p. 60-77 (2009).

45. S. Jin; T. W. Tang; M. V. Fischetti, "Anatomy of Carrier Backscattering in Silicon Nanowire Transistors" in Proc. 13 $3^{\text {th }}$ International Workshop Computational Electronics, 2009 pp. $1-4$

46. J. P. McKelvey and J. C. Balogh, "Flux methods for the analysis of transport problems in semiconductors in the presence of electric fields" Phys. Rev., 137(5A), pp. 1555-1561, Mar. 1965.

47. E. F. Pulver and J. P. McKelvey, "Flux methods for transport problems in solids with nonconstant electric fields," Phys. Rev., 149(2), pp. 617-623, Sep. 1966.

48. A. Lochtefeld and D. A. Antoniadis, "On experimental determination of carrier velocity in deeply scaled NMOS: How close to the thermal limit?" IEEE Electron Device Lett., 22(2), pp. 95-97, Feb. 2001

49. A. Lochtefeld; I. J. Djomehri; G. Samudra; D. A. Antoniadis; "New insights into carrier transport in n-MOSFETs" IBM J. Res. Dev., 46(2.3), pp. 347 - 357 (2002)

50. M.-J. Chen, H.-T. Huang, K.-C. Huang, P.-N. Chen, C.-S. Chang, and C. Diaz, "Temperature dependent channel backscattering coefficients in nanoscale MOSFETs," in IEDM Tech. Dig, pp. 39-42 (2002)

51. V. Barral, T. Poiroux, J. Saint-Martin, D. Munteanu, J. Autran, and S. Deleonibus, "Experimental investigation on the quasi-ballistic transport - Part 1: Determination of a New Backscattering Coefficient Extraction Methodology," IEEE Trans. Electron Devices, 56 (3), pp. 408-419, Mar. 2009.

52. V. Barral, T. Poiroux, D. Munteanu, J. Autran, and S. Deleonibus, "Experimental investigation on the quasi-ballistic transport - Part 2: Backscattering coefficient extraction and link with the mobility," IEEE Trans. Electron Devices, 56 (3), pp. 420-430, Mar. 2009.

53. C. Jeong; D.A. Antoniadis, M. S. Lundstrom, "On Backscattering and Mobility in Nanoscale Silicon MOSFETs" IEEE Trans. Electron Devices, 56(11), pp. 2762 - 2769, Nov. 2009.

54. A. Cros, K. Romanjek, D. Fleury, S. Harrison, R. Cerutti, P. Coronel, B. Dumont, A. Pouydebasque, R. Wacquez, B. Duriez, R. Gwoziecki, F. Boeuf, H. Brut, G. Ghibaudo, T. Skotnicki, "Unexpected mobility degradation for very short devices: A new challenge for CMOS scaling", in IEDM Tech. Dig. pp. 399 (2006)

55. V. Barral, T. Poiroux, S. Barraud, F. Andrieu, O. Faynot, D. Munteanu, J. L. Autran, and S. Deleonibus, "Evidences on the Physical Origin of the Unexpected Transport Degradation in Ultimate n-FDSOI Devices IEEE Trans. on Nanotechnology, 8(2) p. 167 (2009)

56. D. Fleury, G. Bidal, A. Cros, F. Boeuf, T. Skotnicki and G. Ghibaudo, "New Experimental Insight into Ballisticity of Transport in Strained Bulk MOSFETs", in VLSI Tech. Dig. 2009 pp. 16-17.

57. G. Ghibaudo, M. Mouis, L. Pham-Nguyen, K. Bennamane, I. Pappas, A. Cros, G. Bidal, D. Fleury, A. Claverie, G. Benassayag, P. F. Fazzini, C. Fenouillet-Beranger, S. Monfray, F. Boeuf, S. Cristoloveanu, T. Skotnicki, N. Collaert. "Electrical transport characterization of nano CMOS devices with ultra-thin silicon film", Proc. of the International Workshop on Junction Technology, pp. 58 - 63 (2009) 
58. H. Wang, G. Gildenblat, "Scattering matrix based compact MOSFET model", in IEDM Tech. Dig., pp. 125-128 (2002)

59. G. Gildenblat, "One-flux theory of a nonabsorbing barrier "J. Appl. Phys., 91(12), pp. 9883$9886(2002)$

60. S. Martinie, D. Munteanu, G. Le Carval, J.L. Autran, " Physics-Based Analytical Modeling of Quasi-Ballistic Transport in Double-Gate MOSFETs: From Device to Circuit Operation "IEEE Trans. Electron Devices, 56(11), pp. 2692-2702 (2009)

61. A. Khakifirooz, D. Antoniadis, "MOSFET performance scaling-Part I: historical trends," IEEE Trans. Electron Devices 55, p 1391-1400 (2008).

62. A. Khakifirooz, D. Antoniadis, "MOSFET performance scaling-Part II: future directions," IEEE Trans. Electron Devices 55, p 1401-1408, (2008).

63. M. Lundstrom "Nanotransistors: A Bottom-Up View", Proceeding of the ESSDERC, pp. 33 40 (2006)

64. A. Rahman, M. Lundstrom, "A Compact Scattering Model for the Nanoscale Double-Gate MOSFET” IEEE Trans. Electron Devices 49, p 481-489, (2002)

65. R. Clerc, P. Palestri, L. Selmi, "On the Physical Understanding of the kT-Layer Concept in Quasi Ballistic Regime of Transport in Nanoscale Devices," IEEE Trans. Electron Devices, 53(7), pp. 1634 - 1639, (2006).

66. F. Assad, K. Banoo, M. Lundstrom, «The Drift Diffusion Equation revisited » Solid State Electronics, 42 p. 283 (1998).

67. J. H. Rhew, M. Lundstrom, « Drift Diffusion equation for ballistic transport in nanoscale metal-oxide-semiconductor field effect transistors » J. Appl. Phys., 92 p. 5196-5202 (2002).

68. M. Lundstrom and J.-H. Rhew, "A Landauer Approach to Nanoscale MOSFETs", J. Comp. Elec. 1: pp. 481-489, 2002.

69. R. Clerc, P. Palestri, L. Selmi, G. Ghibaudo "Back-Scattering in Quasi Ballistic NanoMOSFETs: The role of Non Thermal Carrier Distributions", proc. of the ULIS conference, p. 125 (2008). Submitted to IEEE Trans. Electron Devices.

70. E. Gnani, A. Gnudi, S. Reggiani, and G. Baccarani, Quasi-Ballistic Transport in Nanowire Field-Effect Transistors, IEEE Trans. Electron Devices, vol. 55, no 11, pp. 2918 - 2930, Nov. 2008.

71. D. Ponton, L. Lucci, P. Palestri, D. Esseni and L. Selmi, "Assessment of the Impact of Biaxial Strain on the Drain Current of Decanometric n-MOSFET", in Proc. ESSDERC, 2006, pp.166-169.

72. M. Lundstrom, "On the mobility versus drain current relation for a nanoscale MOSFET", IEEE Electron Device Lett., 22, pp. 293-295 (2001)

73. I. Pappas, G. Ghibaudo, C.A. Dimitriadis, C. Fenouillet-Béranger, «Backscattering coefficient and drift-diffusion mobility extraction in short channel MOS devices », Solid State Electronics, 53, pp. 54-56 (2009).

74. M. Shur, "Low ballistic mobility in submicron HEMTs", IEEE Electron Device Lett., 23, pp. 511-513 (2002).

75. F. J. Wang and M. Lundstrom, "Ballistic transport in high electron mobility transistors", IEEE Trans on Electron devices, 50, pp. 1604-1606 (2003).

76. G. Ghibaudo, "A new method for the extraction of MOSFET parameters", Electronics Lett., 24, pp. 543-544 (1988).

77. K. Romanjek, F. Andrieu, T. Ernst, and G. Ghibaudo, "Improved split C(V) method for effective mobility extraction in sub $0.1 \mu \mathrm{m}$ Si MOSFETs", IEEE Electron Device Lett., 25, pp. 583-585 (2004).

78. F. Lime, G. Ghibaudo, F. Andrieu, J. Derix, F. Boeuf, T. Skotnicki, "Low temperature characterization of effective mobility in uniaxially and biaxially strained nMOSFETs", Solid State Electronics, 50, pp. 644-648 (2003)

79. G. Bidal, D. Fleury, G. Ghibaudo, F. Boeuf and T. Skotnicki, "Guidelines for MOSFET Device Optimization accounting for L-dependent Mobility Degradation", in Proc. of Silicon Nanoelectronics Workshop, 2009. 